\title{
Pollen Mother Cell Analysis of Intraspecies Hybrid of Gossypium arboreum Linn., Indicating Secondarily Balanced Polyploidy ${ }^{1}$
}

\author{
L. D. Vijendra Das ${ }^{2}$ and S.W. Mensinkai ${ }^{3}$ \\ Division of Botany, College of Agriculture and Research Institute \\ Dharwar, India
}

Received March 6, 1967

\section{Introduction}

The basic chromosome number 13 of the species Gossypium arboreum suggests the evolutionary process as being different from euploidy. Aneuploidy might have played an important role in this process. Secondary pairing which is an indication for the homology of chromosomes and secondary polyploidy has been observed in this species. The evidences point out the possibility of the species, G. arboreum being a secondary, polyploid and the present investigations lend support to this view.

Review of literature:-Chandrasekharan and Parthasarathy (1960) were of the opinion that secondary pairing was an indication of secondary polyploidy. According to Darlington (1963) secondary polyploidy with new basic number arose as a result of the addition or reduction of whole chromosomes. Hays et al. (1955) opined that secondary pairing in old world cottons with $(2 n=26)$ might suggest the probable origin of secondary polyploids and the probable composition of the haploid number 13 being 5 duplicate chromosomes and a trisome. Harland (1939) stated that two malvaceous plants with $(n=6)$ crossed to form secondary polyploids with $(n=13), 5$ chromosomes having duplicated twice and one three times, and that the ancestral tetraploid subsequently diverged into several groups without any change in the chromosome number; two of the descendant groups found in North America were the Davidsonii-Klotzschianum and Thurberi, armourianum aridum Series; another main group differentiated, into stocksii and Sturtii now prevailing in India and Arabia and Australia respectively. Anomalum spread in Africa while arboreum-herbaceum group was distributed widely throughout Africa, south East Asia and Polynesia.

13 deeply stained and 13 lightly stained chromosome pairs were observed in metaphase (I) of P.M.C. of one of the preparations of a new world cotton by Ellenhorn (1936) who attributed it to amphidiploidy. He further noticed secondary pairing in which 24 out of the 26 chromosome pairs participated and was always between similarly stained chromo. somes. These results led him to conclude that the new world cottons were modified octoploids.

Skovsted (1937) observed secondary association in wild America species indicating 6 to be the basic number. Stephens (1942) from his studies concluded that diploid species were secondary polyploids. Webber (1934) observed 1 or 2 quadrivalents in certain hybrids between species with $n=26$ and $n=13$ and confirmed, the hypothesis that the basic number 13 arose through modified tetraploidy.

1 This work constitutes a part of the Dissertation of the first author for his degree in Master of Science in Agriculture, Karnatak University, Dharwar under the guidance of the Second author.

${ }^{2}$ and ${ }^{3}$ present address: Central Sugarcane Breeding Institute, Coimbatore, India; Director of Instruction, (Agriculture), College of Agriculture and Research Institute, Dharwar, India. 
Shastry and Swaminathan (1960) observed specific secondary association of the end-toend, side-to-side, and end-to-side type in meiotic studies conducted on a plant belonging to $G$. barbadense with $(\mathrm{n}=26)$ where among the chromosomes that participated were 1 big and 1 small, 2 big and 1 small, 3 big and 1 small and 3 big univalents. The reason for the association of big and small chromosomes was probably the homology between a few $A$ and $\mathrm{D}$ genome chromosomes.

Jacob $(1941,1942-43)$ studied the somatic chromosomes of arboreum, herbaceum and Stocksii and inferred that the basic number was 7 having the constitution $4 \mathrm{~b}-2(\mathrm{~b}=$ basic number 7). It was speculated that they were evolved by hybridization of two 7 chromosome types followed by chromosome duplication and loss of two chromosomes.

In the malvaceous species Malva sylvestris $\mathrm{L}(\mathrm{n}=21)$, secondary pairing was observed by Roy and Sinha (1961) at M I indicating the probable origin due to polyploidy. The same workers and Skovsted (1935) observed the presence of several basic numbers in the malvaceous species and concluded that different species evolved independently.

In sweet potato, Ting and Kehr (1953) observed characteristic groupings at M I due to the general affinity of relatively homologous chromosomes.

Nishiyama (1956) suggested that the original basic number of a species could be ascertained from the secondary pairing of chromosomes.

In the common weed Launaea nudicaulis Less, a member of Cichoreae, Murthy (1950) noticed secondary pairing and he concluded that the species was not a true diploid with $2 \mathrm{n}=18$.

Swanson (1957), discussing the pairing behaviour of chromosomes remarked that the exactness of synapsis pointed to the existence of attraction forces of extraordinary specificity.

Darlington (1928) and Lawrence (1931) ascribed secondary pairing to the affinity between chromosomes.

According to $\mathrm{Hu}(1962)$ secondary polyploidy might have played a role in the evolution of the present species of Oryza with $\mathrm{n}=12$.

During the pachytene analysis of Ricinus communis Jakob (1957) noticed secondary association in early diakinesis, he postulated that primary and secondary pairings could be attributed to the same origin.

In the study of meiocytes of diploid pomoideae, Darlington and Moffet (1930) found that 17 bivalents were distributed in 3 groups of 3 bivalents and 4 groups of 2 bivalents. They interpreted that the tribe Pomoideae originated from diploid species with $n=7$ by the doubling of the entire set plus the addition of a third partial set consisting of 3 of the original 7 bivalents.

According to Stebbins (1950) the simplest way of changing the basic number would be by the duplication of whole chromosomes, and in many cases the evidences were indirect since these higher categories were so old that the concerned ancestral species were almost extinct. Polyploidy thus could not be repeated experimentally.

\section{Materials and methods}

The flower buds in the $\mathrm{F}_{1}$ hybrids of intraspecies of $G$. arboreum L., (G. arboreum var. virnar $\times G$. arboreum var. rozi) were analysed. The younger flower buds in which the corolla tip was slightly visible were fixed in a fixative containing $3 \mathrm{cc}$ of absolute alcohol; 2 c.c. of chloroform and 1 c.c. of propionic acid. The buds were kept in the fixative for 5 hours and then transferred to $0.25 \%$ of colchicine to destroy the spindle mechanism. After 15 hours in the aqueous solution, the buds were transferred to $70 \%$ alcohol for preservation and then smeared in $0.5 \%$ to $1 \%$ of propiono carmine.

\section{Observations}

The meiotic cycle was regular. 13 bivalents were formed at metaphase 


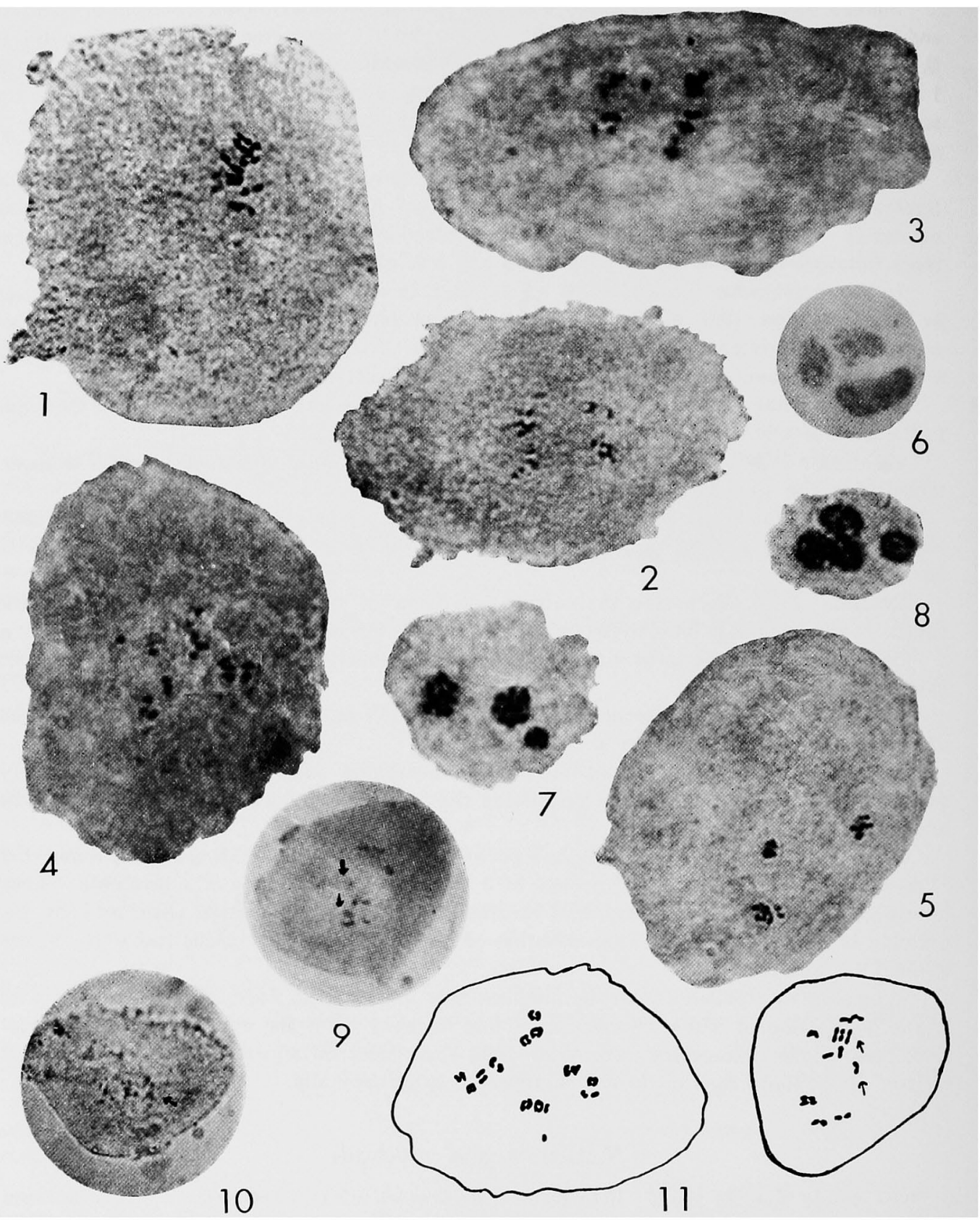

Figs. 1-12. Normal metaphase and secondary association in the meiocytes and pollen mitosis $\times 800$. 1, normal metaphase I showing the arrangement of 13 bivalents in the equatorial plate. 2, early metaphase I. 3 groupings of bivalents. (2 II plus 3 II Plus 8 II). 3 , early metaphase I, 4 groupings of bivalents. (2 II plus 3 II plus 4 II Plus 4 II). 4, early metaphase I. 5 groupings of bivalents. (2 II plus 1 II plus 3 II Plus 4 II plus 3 II). 5 , early metaphase I. 3 very distant groupings of bivalents. Bivalents could not be counted. 6, early telophase I. 2 groupings in one daughter cell. 7, late telophase I. A micronucleus in a daughter cell. 8, late telophase I. 4 micronuclei in a cell. 9, pollen mitotic metaphase, showing end-to-end association as well as side-to-side association. The top arrow shows 3 univalents which are grouped closely. The lower arrow shows a univalents which is out of focused. 10, pollen mitotic metaphase. 3 groupings of univalents. The arrow shows a group. 11-12, camera lucida drawings of Figs. 4 and 9 showing the details of groupings. 
I and the chromosomes were distributed regularly to the poles. Four microspores were produced and the distribution of chromosomes in the pollen mitosis was regular. Occasionally, secondary pairing was observed in nine cells. The details with regard to the cytological behaviour in each of these nine cells are given below :-

\begin{tabular}{|c|c|c|c|}
\hline $\begin{array}{l}\text { Serial } \\
\text { No. }\end{array}$ & $\begin{array}{l}\text { Secondary association at meiosis } \\
\text { Early metaphase I }\end{array}$ & $\begin{array}{l}\text { No. of } \\
\text { groups }\end{array}$ & Frequency \\
\hline 2. & 2 II plus 3 II plus 8 II (Fig. 2) & 3 & 1 \\
\hline 3. & 2 II plus 3 II plus 4 II plus 4 II (Fig. 3 ) & 4 & 1 \\
\hline 4. & $\begin{array}{l}2 \text { II plus } 1 \text { II plus } 3 \text { II plus } 4 \text { II plus } 3 \text { II } \\
\text { (Fig. 4) }\end{array}$ & 5 & 1 \\
\hline 5. & Bivalents could not be counted (Fig. 5) & 3 & 1 \\
\hline 6. & $\begin{array}{l}\text { Telophase I (early) } 2 \text { groups } \\
\text { in one daughter cell (Fig. } 6 \text { ) } \\
\text { Telophase I (Late) }\end{array}$ & 3 & 1 \\
\hline 7. & A micronucleus in one daughter cell (Fig. 7) & 3 & 1 \\
\hline 8. & $\begin{array}{l}4 \text { micronuclei in a cell (Fig. 8) } \\
\text { Pollen mitosis (metaphase) }\end{array}$ & 4 & 1 \\
\hline 9. & $\begin{array}{ll}2 & \text { I } \text { end-to-end pairing } \\
3 & \text { I side-to-side pairing } \\
1 & \text { I }\end{array}$ & & \\
\hline & $\begin{array}{ll}2 & \text { I side-to-end pairing arriving closly } \\
1 & \text { I } \\
2 & \text { I side-to-side pairing } \\
2 & \text { I end-to-end pairing arriving closely (Fig. 9) }\end{array}$ & 5 & 1 \\
\hline 10. & Univalents could not be counted & 3 & 1 \\
\hline
\end{tabular}

\section{Discussion}

In the intraspecies $F_{1}$ hybrids of $G$. arboreum $L$, meiosis was regular but occasional secondary association was noticed. In the early Metaphase I, the characteristic groupings of bivalents revealed their affinity. At the end of Metaphase I the bivalents separated normally. Sometimes the affinity was greater and hence 3 very distantly placed groupings were observed at Metaphase I (Fig. 5). It is doubtful whether such bivalents would separate and reach the poles normally. This was noticed in early telophase I where 2 groupings were observed in a daughter cell (Fig. 6). Secondary pairing also resulted in micronucleus at late telophase I (Fig. 7). The Fig. 8 revealed that the 4 groupings which occurred at Metaphase I, resulted in 4 micronuclei at telophase I and this explains the closest relationship of chromosomes. The occurrence of micronucleus which generally brings in loss of a few bivalents could explain the observation of PMC with 10 bivalents by Gerstel (1955). This is discussed in a separate paper. Secondary pairing was also exhibited in mitotic division and was noticed in pollen mitosis (Figs. 9 and 10). 
The presence of secondary pairing indicates that the diploid cotton might not be a true diploid but possibly a secondary polyploid.

The hypothesis of Harland (1939) that 5 chromosomes repeated twice and one thrice seems plausible. Thus two malvaceous plants, one with $n=6$ and another with $n+1=7$ crossed to form a trisome and in the course of evolution, due to non reduction of gametes, the chromosome complement was doubled to form $2 n=26$. Accordingly,

$$
\begin{aligned}
& (\mathrm{n}=6) \text { A B C D E F } \times(\mathrm{n} \text { Plus I) AA B CD EF }=7 \\
& (2 \mathrm{n} \text { plus } \mathrm{I})=13 \text { AAA BB CC DD EE FF } \\
& \text { (non reduction of gametes) } \\
& (4 \mathrm{n} \text { plus } 2)=26 \text { AAAAAA BBBB CCCC DDDD EEEE FFFF }
\end{aligned}
$$

The name hexasomic tetraploid may be attributed to the existing diploid cottons and the amphidiploid cottons are complex octoploids. By the time the natural crossing of Old World diploid and New World diploid cottons took place, the chromosomes were differentiated. Let us assume the chromosome complement of the old World Cotton (AAAAAA BBBB CCCC DDDD EEEE FFFF) as $\mathrm{A}$ genome and the chromosome complement of New World cotton ( $\mathrm{A}^{\prime} \mathrm{A}^{\prime} \mathrm{A}^{\prime} \mathrm{A}^{\prime} \mathrm{A}^{\prime} \mathrm{A} \mathrm{B}^{\prime} \mathrm{B}^{\prime} \mathrm{B}^{\prime} \mathrm{B}^{\prime} \mathrm{C}^{\prime} \mathrm{C}^{\prime} \mathrm{C}^{\prime} \mathrm{C}^{\prime} \mathrm{D}^{\prime} \mathrm{D}^{\prime} \mathrm{D}^{\prime} \mathrm{D}^{\prime} \mathrm{E}^{\prime} \mathrm{E}^{\prime} \mathrm{E}^{\prime} \mathrm{E}^{\prime} \mathrm{F}^{\prime} \mathrm{F}^{\prime} \mathrm{F}^{\prime} \mathrm{F}^{\prime}$ as $\mathrm{D}$ genome. The natural Hybrid,

\section{AAA BB CC DD EE FF}

$\mathrm{A}^{\prime} \mathrm{A}^{\prime} \mathrm{A}^{\prime} \mathrm{B}^{\prime} \mathrm{B}^{\prime} \mathrm{C}^{\prime} \mathrm{C}^{\prime} \mathrm{D}^{\prime} \mathrm{D}^{\prime} E^{\prime} \mathrm{E}^{\prime} \mathrm{F}^{\prime} \mathrm{F}^{\prime}$ was sterile.

The entire chromosome complement was doubled.

\section{AAAAAA BBBB CCCC DDDD EEEE FFFF}

$\mathrm{A}^{\prime} \mathrm{A}^{\prime} \mathrm{A}^{\prime} \mathrm{A}^{\prime} \mathrm{A}^{\prime} \mathrm{A}^{\prime} \mathrm{B}^{\prime} \mathrm{B}^{\prime} \mathrm{B}^{\prime} \mathrm{B}^{\prime} \mathrm{C}^{\prime} \mathrm{C}^{\prime} \mathrm{C}^{\prime} \mathrm{C}^{\prime} \mathrm{D}^{\prime} \mathrm{D}^{\prime} \mathrm{D}^{\prime} \mathrm{D}^{\prime} \mathrm{E}^{\prime} \mathrm{E}^{\prime} \mathrm{E}^{\prime} \mathrm{E}^{\prime} \mathrm{F}^{\prime} \mathrm{F}^{\prime} \mathrm{F}^{\prime} \mathrm{F}^{\prime}$.

The resulting hybrid was fertile and the New World allotetraploid cottons are in fact 12 somic allo octoploids. Thus in the diploid cotton due to the presence of more homologous partners, secondary association would have occurred. During the course of evolution, diploidisation took place by micro inversions and mutations under selection pressure and hence there was no multivalent formation and meiotic sterility.

The statement of Jacob (1941-1942-43) that the diploid cottons evolved by hybridization of two 7 chromosome types, followed by chromosome duplication and loss of 2 chromosomes is difficult to accept because generally the loss of 2 chromosomes would be at random resulting in permanent univalents, $24+1+1$.

The existing malvaceous species Malvastrum tricuspidaum A. Gray, Sida acuta Burm, and Abutilon indicum Don, with their chromosome as multiples of $n=6$ (Roy and Sinha 1961) support the hypothesis that the diploid cottons could have had 6 as the basic number. The fact that the allied genera viz Kokia (Hawaii) and Gossypoides (East Africa) with $2 \mathrm{n}=24$ arose as allopolyploids from 6 pairs of chromosomes (Harland 1939) further strengthes it. It is possible that in course of time secondary pairing may 
disappear due to micro inversions and mutations and the $n=13$ cottons may behave as true diploids.

\section{Summary and conclusions}

In the cytological analysis of PMC of arboreum secondary pairing was noticed. Three, four and five groupings of bivalents were observed at early metaphase I. In early telophase I, two groupings were noticed in one daughter cell. In late telophase I, a micronucleus and in another cell 4 micronuclei were noticed. Secondary pairing was also noticed in pollen mitosis. The cause for secondary association and for the formation of separate nuclei was attributed to greater affinity of homologous chromosomes. The original basic number of chromosomes may be inferred to be 6 and the diploid species may be considered to be secondarily balanced polyploids (hexasomic tetraploids). For the amphidiploid new world cottons, the name 12 somic allo octoploid is suggested.

Acknowledgment: It is pleasure to express the author's sincere gratitude to the Principal L. S. S. Kumar. (Retired), College of Agriculture, Poona for encouragement while preparing this paper.

\section{Literature cited}

Chandrasekharan, S. N. and Parthasarathy, S. V. 1960. Cytogenetics and plant Breeding. P. Varadachary \& Co., Madras. P. 243.

Darlington, C. D. 1928. Studies in Prunus. J. Genet. 19: 213-51.

- 1963. Chromosome Botany, George Allen and Unwin Ltd., Ruskin House Museum Street, London, P. 99

* - and Mofett, A. A. 1930. Primary and secondary chromosome balance in Pyrus. J. Genet. 22: 129-51.

Ellenhorn, J. 1936. Differential chromosome staining at meiosis in G. Peruvianum. Cytologia 2: 213-8 (German) Abst. from plant Breed Abstr. 7: 67). (Condensed from abstr. Bibilio of Cotton Breed. and Genet. 1900-1950 P. 56-7. 1954).

Gerstel, D. U. 1955. A pollen mother cell of Asiatic cotton with only ten pairs of chromosomes. Cytologia 20: 197-8.

Harland, S. C. 1939. The Genetics of Cotton. Jonathan Cape. 30 Bedford Square, London. P. $46-8$ and $176-7$.

Hayes, H. K. 1955. Methods of Plant Breeding. McGraw Hill Book Company, New York, London, Toronto. 2nd Edition. P. 239.

Hu, C. H. 1962. Studies of meiosis in Oryza species with special reference to secondary association. Cytologia 27: 285-94.

*Jacob, K. T. 1941. Preliminary observation on the chromosome morphology in Asiatic cottons with special reference to their phylogency and inter-relationships, 2nd Conf. Cott. Gr. Probl. India, I.C.C.C. Bombay. P. 42-5.

* - 1942-43. Studies in Cotton. Morphology of somatic chromosomes in eight types of Asiatic Cotton. Trans. Bose Research Institute 15: 17-27.

Jakob, K. M. 1957. Secondary association in the castor oil plant. Cytologia 22: 380-91.

Lawrence, W. J.C. 1931. The secondary association of chromosomes. Cytologia 23: 38199.

Murthy, M. H.S. 1950. A preliminary note on the karyotype of Launaea nudicaulis Less. 
Curr. Sci. 19: 254.

Nishiyama, I. 1956. Basic numbers in the polyploidy of Saccharum. J. Hered. 47: 95.

Roy, R. P. and Sinha, R. P. 1961. Meiotic studies in some malvaceous species. Curr. Sci. 30: $26-7$.

Sastry, G. R. K. and Swaminathan, M. S. 1960. Chromosome associations in haploid Gossypium barbadense Curr. Sci. 29: 398-400.

Skovsted, A. 1935. Chromosome numbers in the Malvaceae. Indian J. Genet. 31: 263-96 (From Abst. Bibilio. of Cotton Breed. and Genet. 1900-1950 P. 199-200 1954).

- 1937. Cytological studies in cotton chromosome conjugation in interspecific hybrids. J. Genet. 34: 97-134. (From Abst. Bibilio. of Cotton Breed. and Genet 1900-1950 P. 199-200. 1954).

Stebbins, G. L. 1950. Variation and Evolution in Plants. Columbia University Press. New York P. 359-60 and 451-2.

Stephens, S. G. 1942. Colchicine produced polyploids in Gossypium. 1. An autotetraploid, Asiatic Cotton and certain of its hybrids with wild diploid species. J. Genet. 44: 272-95 (From Abst. Bibilio. of Cotton Breed. and Genet. 1900-1950. P. 202-3. 1954.)

Swanson, C. P. 1957. Cytology and Cytogenetics. Englewood Cliffs. New Jersey, P. 210.

Ting. Y. C. and Kehr. A. E. 1953. Meiotic studies in the sweet potato. J. Hered. 44: 207-11.

Webber, J. M. 1934. Interspecific hybridization in Gossypium and the meiotic behaviour of $F_{1}$, plants. J. Agric. Res. 51: 1047-70. (Condensed from Pl. Breed. Abst. 6: 406-7) (From Abstr. Bibilio of Cotton Breed and Genet. 1900-1950. P. 227-8. 1954).

* Original not seen. 